\title{
Hospital associated bacteremia in two Tunisian intensive care units
}

\author{
Nakhli M.S., Kahloul M., Chakroun A., Harrathi M.A., Mhamdi S. \\ Sahloul Hospital, Dept of Anaesthesiology \& Intensive Care, Sousse, Tunisia \\ Introduction:
}

Hospital associated bacteremia (HAB) represents a public health challenge because of a high morbi-mortality. It is more frequent and severe in the intensive care environment. In Tunisia, we don't have a monitoring network. The aims of our study are to determine the annual incidence of $\mathrm{HAB}$ in ICU environment and to study the associated risk factors.

\section{Methodology:}

It is about a longitudinal descriptive study led in surgical and medical ICU of Sahloul teaching hospital during one year between July, 2010 and July, 2011 and based on the French protocol REA-RAISIN 2009. All the patients hospitalized beyond 48 hours were included.

\section{Results:}

Our study included 301 patients. The average age was $45 \pm 21$ years with male domination. The average IGS II scale was $25 \pm 17$. The incidence of bacteremia was estimated at $7 \%$. The density of global incidence was 6,26 for 1000 days of hospitalization and the density of specific incidence was 10,26 for 1000 days for central venous catheterization (CVC). Twenty one germs were isolated. The most frequently isolated were Acinetobacter baumanii in $28,6 \%$ of cases (6/21 germs), Staphylococcus aureus and Klebsiella pneumoniae in $14,3 \%$ of cases (3/21 germs) each (Graphic 1$)$. The univariate analysis showed a statistically significant association (table1), for the age $(p=0,039)$, the IGS II scale $(p=0,027)$, the intubation $\left(p<10^{-3}\right)$, the duration of intubation $>10$ days $(p=0,001)$, the tracheotomy $\left(p<10^{-3}\right)$, the urinary catheter $\left(p<10^{-3}\right)$, the duration of urinary catheter superior to six days $\left(p<10^{-3}\right)$, the central venous catheterization $(p<10$ $3)$ and its duration $\left(p<10^{-3}\right)$. Besides, the multivariate analysis highlighted as independent risk factor, the intubation $(p=0,022)$ and the tracheotomy $(p=0,003)$.

Graphic 1:The most frequently isolated bacteria

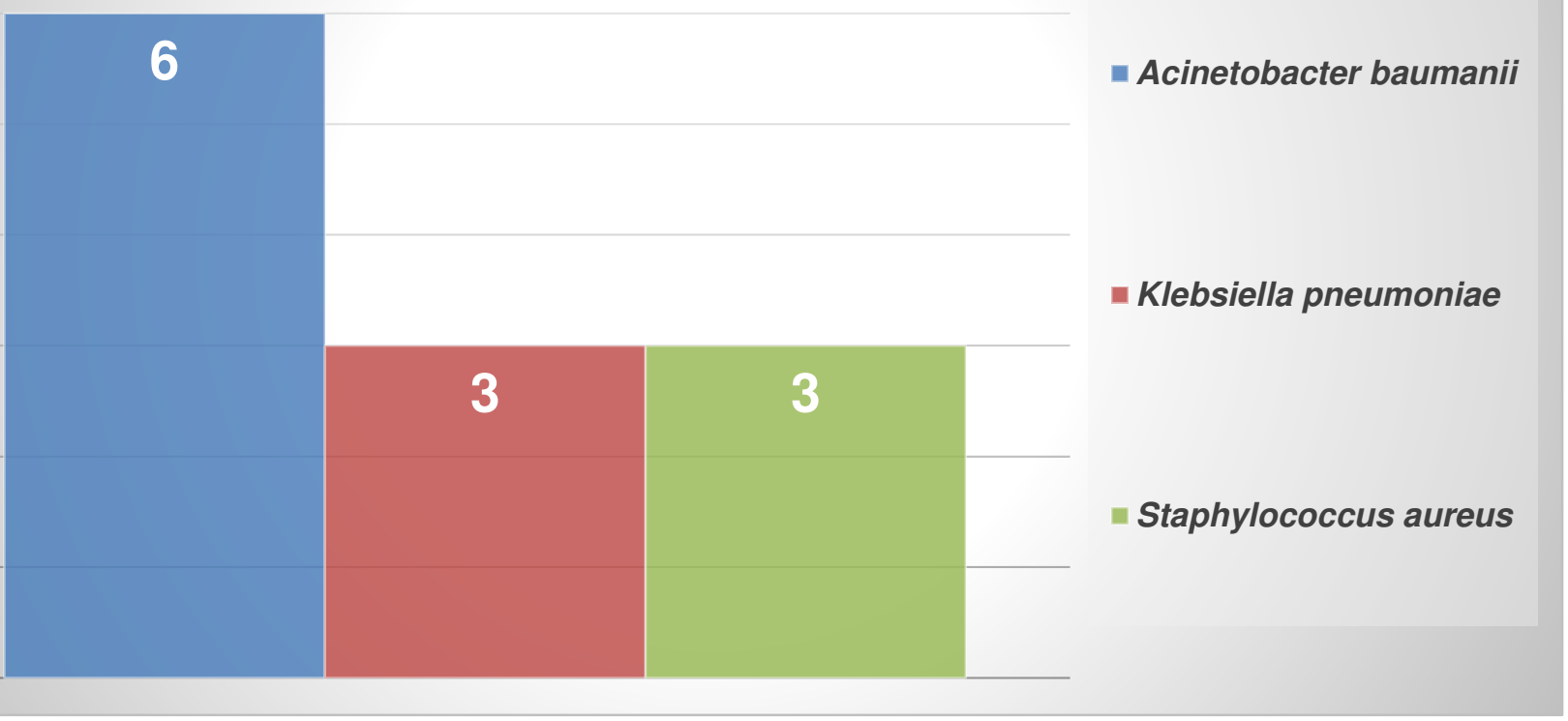

\section{Discussion:}

The density of incidence (DI) for 1000 days of hospitalization varies according to countries. It is lower than 1 in the USA, Canada and Germany. It is 1,13 in China and 3,53 in France (REA-RAISIN 2014) and it's more important in developing countries such as Tunisia $(6,2)$ and Morocco $(17,82)$.

\section{References:}

1. Surveillance des infections nosocomiales en réanimation adulte. Réseau REA-Raisin, France Résultats 2014. Saint-Maurice : Institut de veille sanitaire ; 2016. $48 \mathrm{p}$.

Raisin. Surveillance des infections nosocomiales en réanimation adulte. Réseau REA-Raisin, France, Résultats 2012. Saint-Maurice : Institut de veille sanitaire ; 2013. 38 p.
About the bacteriological profile, we note an ascendancy of the positive cocci gram (PCG) compared with negative gram bacilli (NGB) in Canada (66,5\% vs. $22.3 \%$ ) and in Germany (52,3\% vs. $34.3 \%$ ). The NGB prevails especially in developing countries. In Morocco, they have a $73 \%$ rate, dominated by Acinetobacter baumannii and Pseudomonas aeruginosa. In France, the REARAISIN 2014's study (1) pointed the predominance of NGB in $46,7 \%$ of $\mathrm{HAB}$ cases (Enterobacteria in $34,6 \%$ of cases including ESBL in $7,5 \%$ and Pseudomonas aeruginosa in 8,5\%), over PCG (41\%), dominated by Staphylococcus epidermidis $(11,4 \%)$. The available human and material resources and the strategies adopted by these countries to fight against the HAB problem, explain largely, the disparity of these results.

Table 1 : Risk factors involved in HAB after univariate analysis

\begin{tabular}{lc|}
\hline \multicolumn{1}{c}{ Risk factors } & p \\
\hline Age & 0,039 \\
\hline IGS II score & 0,027 \\
\hline Intubation & $<10^{-3}$ \\
\hline Intubation's duration > 10 days & 0,001 \\
\hline Tracheotomy & $<10^{-3}$ \\
\hline Urinary catheterization & $<10^{-3}$ \\
\hline Urinary catheterization's duration $>06$ days & $<10^{-3}$ \\
\hline Central venous catheter (CVC) & $<10^{-3}$ \\
\hline CVC's duration & $<10^{-3}$ \\
\hline
\end{tabular}

The age and the sex are not any more involved as risk factors. The Rea-Raisin 2012's study (2) retained, as risk factors, a high IGS ॥ score, the mechanical ventilation (intubation for a duration $>10$ days, re-intubation and tracheotomy), the CVC (site of insertion, quality of maintenance and duration of insertion) and the urinary catheterization (especially for duration $>6$ days).

\section{Conclusion:}

Our study's data confirm the major role which play the invasive devices and the duration of their implementation, inciting to revise the professional practices in intensive care units relative to the indications and the application time of these devices.

Geneva, Switzerland 